\title{
Pela Paz
}

\section{João Arruda}

Em uma dessas longas esperas na sala de notabilidade scientifica, conversavam os clientes aguardando vez para serem attendidos. Quasi sempre são as senhoras que falam: os homens ouvem. Uma das que se aborreciam com a demora dizia a outra o que fôra para ella a campanha de 1932: "Voltou meu filho, mas mutilado, um infeliz para o resto da existencia" Retorquiu a outra: "E o meu... não voltou". Duas saudosas lagrimas rolaram por sua face, e foram a prova da dor da infeliz mãe.

Reflecti sobre a inutilidade dessa dor, e acudiu-me ao espirito a campanha que na America do Norte fazem as mulheres em prol da paz: "Educating for Peace" Copiar essa lucta, muito mais salutar que a pela gloria guerreira, eis o que cumpre ao sexo feminio (Krehbiel, Nationalism, pags. 227 e 228, Allen,War, pags. 81 e s. BArthelemy dE LigT, Contre la Guerre Nouvelle, Int. e pags. 131 e 142), que tão relevantes serviços presta sempre nos hospitaes de sangue, como succedeu na emprehendida por nosso Estado, em prol da constitucionalização do Brasil.

Parece que as doutrinas biblicas muito influiram para dar ao povo judeu seu espirito pacifico, que é nelle mantido até nossos dias. Fóra a conhecida promessa de Isaias, a todo momento se deparam nos textos escrituriticos conselhos em favor da paz, contra o pensamento geral dos povos antigos, embora tolerassem os principios religiosas dos hebreus a guerra contra os gentios. (KrEHBIEL, Nationalism, pags. 150 e segs.). 
Tres escolas ha sobre a guerra. -

A 1. ${ }^{\text {a }}$ sustenta que a guerra é sancta, factor do progresso: é aconselhavel. E' a de Donoso Contez, Moltke e Mussozini. Dos discursos de Donoso Cortez hoje poucos se lembram - Ha o doutrinado por Moltke, e tão frequentemente repetido pelos que combatem pela paz. Eis suas conhecidissimas palavras: "A guerra é sancta; de instituição divina; é uma das leis sagradas do mundo; ella mantem nos homens todos os grandes e nobres sentimentos; a honra, o desinteresse, a virtude, a coragem, e os impede, em uma palavra, de cahirem no mais torpe materialismo".

Um sem numero de vezes têm os grandes espiritos affirmado haver uma observação inexacta da parte do marechal: a guerra não desenvolve os sentimentos nobres, unicamente os faz apparecer, mostrar que existiam, comquanto sopitados por não serem necessarios em plena paz. MussoLiNI nada fica a dever a Moltke. O artigo que publicou, em 1932, na Encyclopedia Italiana, é um dos mais enthusiasticos hymnos á guerra. A idea fundamental é a mesma de Donoso e Moltke: a guerra é um factor do progresso. Eis alguns dos topicos do seu artigo. "A doutrina que é fundada no damnoso postulado da paz é contrária ao fascismo". Pouco depois: "O fascismo nega a doutrina da felicidade, do bem estar, que reduziria o homem ao nivel dos animaes inferiores, os quaes só cuidam de uma coisa engordar e bem alimentar-se - e degradaria a humanidade á existencia puramente physica". Nega o direito da maioria, pelo simples facto de ser maioria, de governar, nega a illusão (sic) da soberania do numero, e attribue ás forças occultas e irresponsaveis a verdadeira soberania. Fazendo a apologia do imperialismo diz: "Para o fascismo o crescimento do imperio, isto é, a expansão da nação é essencial manifestação de vitalidade, ao passo que seguir rumo opposto é indicio de decadencia", Ha um ponto, algum tanto eccletico, em que me leva Mussolinr ao estudo da 2.a doutrina por mim indicada linhas acima. E' o em que affirma 
que o "fascismo não crê nem na utilidade, nem na possibilidade da paz perpetua" Ajunta: "O fascismo repudia a doutrina do pacifismo, nascida da renuncia á lucta, e que constitue um acto de covardia em face do dever de sacrificio" E' illimitada a admiração de Mussolını por Moltke, BISMARCK e outros individuos que elle diz serem antiliberaes. Segue o fascismo direcção oposta á dos hedonistas ou melhor eudemonistas para os quaes é o Estado instituido "ut degant cives feliciter"

Antes de passar á 2." doutrina, direi que, felizmente para a humanidade, só no papel manifestou Mussolini suas ideas contra a paz. Fóra a guerra na Ethiopia, nenhuma outra campanha emprehendeu, e até mesmo negou tivesse o governo italiano tido responsabilidade pela ida de voluntarios italianos a Guadalajara, na Hespanha. Figure-se um Napoleão I, que, em vez de escrever artigos na Encyclopedia, atormentasse o genero humano com seu imperialismo, levando os povos ao celebre ufa! de allivio, quando elle morreu!.

Merece, sem dúvida applauso e admiração a parte do fascismo que préga o altruismo, a abnegação, o sacrificio, o estoicismo, no sentido vulgar do vocabulo. Infelizmente acha-se intimamente unida á em que é feita a apologia da guerra. Dil-o o proprio Mussolini na obra publicada em francez sob o titulo "Le Fascisme, Doctrine, Institutions". Referindo-se á concepção da vida segundo o fascismo diz: "Une vie où l'individu, par l'abnegation de lui même, réalise cette existence toute spirituelle qui fait sa valeur d'homme" Logo após diz que "le fascisme repousse le pacifisme, qui chache une fuite devant la lutte et une lâcheté devant le sacrifice" Em seguida faz a apologia da guerra "qui, seule, porte au maximum de tension toutes les energies humaines et imprime une marque de noblesse aux peuples qui ont le courage de l'affronter" Sem ambages, afirma que é o fascismo antiliberal e antiindividualista.

A 2." doutrina é a que sustenta ser um sonho irrealizavel a paz. E' a geralmente seguida. Creio que é a de 
quasi todos os diplomatas. No último congresso sul americano, de Montevideo e Buenos Aires, pelas irradiações dos discursos ,notei o desanimo que tinham os grandes e velhos diplomatas cada vez que havia uma proposta tendente, já não á paz universal, mas unicamente, ao menos, á americana. Dentre os grandes espiritos que não crêem nas tendencias pacificas do homem está Onesimo Reclus que, descrevendo os tempos prehistoricos, observa que, mesmo então, quando o homem estava constantemente sob a ameaça do ataque dos ferozes animaes antediluvianos, só pensava em aggredir seu semelhante, e devoral-o! Peço licença para emittir minha opinião. Sempre houve e haverá homens e animaes com tendencia para o mal. Si alguma vez cahir de novo a humanidade nas garras de um Napoleão I, surgirá guerra terrivel, não menos damnosa que a do começo do seculo XIX. Não quer isto porém dizer que não se deva tentar diminuir as probabilidades de um tremendo cataclysmo como o foi o da denominada epopéa de Bonaparte.

Passo á 3. ${ }^{a}$ escola. Esta confia na realização da prophecia de Isaias: o advento de uma éra em que as espadas sejam convertidas em instrumentos de trabalho, em que reine a paz completa entre os homens. Não se pode dizer seja isto impossivel, tomadas as providencias que aos pacifistas aconselha a prudencia: é admissivel se ponham obstaculos aos factores da guerra, de modo a tornar-se ésta impossivel. Deve porém a humanidade esperar por esse tempo durante muitos seculos. No proprio Novo Continente, viram-se as luctas dos norte-americanos em Haiti, em Nicaragua e contra tantos povos fracos. A guerra do Chaco é recentissima. Passo á segunda parte deste artigo. Vou referir-me aos factores actuaes da guerra, afim de esclarecer os pacifistas sobre o meio de os conjurar. Será meu guia Harry Elmer Barnes em sua notavel obra World Politics in modern Civilization. Não menos impressionou-me a obra de KREHBIEL intitulada Nacionalism, War and Society. 
O sinistro fator do nacionalismo actua nas classes menos cultas; o capitalismo, nas médias, e finalmente o imperialismo, nas superiores, ou nas dos dirigentes, nos homens do governo. Como se viu, linhas acima, é este ultimo coefficiente, a tecla em que bate sempre Mussolini.

Classificam-se as causas das guerras em biologicas, psychologicos e sociologicas. Nas biologicas entra, em $10^{\circ}$ lugar o temor de falta de alimentos, e era a mais importante entre os selvagens. Os governos não se satisfazem com o livre cambio, importante factor da paz (KreHbiel, Nationalism, pag. 229) : querem ter colonias por motivos politicos. Assim pois entre os povos civilizados não apparece desacompanhada de outro motivo a procura de alimentos: ha a gloria de mandar, na phrase de Camões. $02 .^{\circ}$ factor é muito mais perigoso riue o $10^{\circ}$ por mim indicado: é a inclinação de certos homens e de certos povos para a lucta. Isto se mostra mesmo entre os selvagens e os animaes inferiores: a lucta pela lucta, pelo prazer da victoria, embora sem vantagens para o vencedor. Digna de menção é a lenda dos Mbayas, narradas por Southey (Historia do Brasil, 5/499): eram guerreiros por indole.

Diz-se, em 3. logar, que a tendencia para o aperfeiçoamento da raça é outro importante motivo de guerra! Cada povo se julga superior aos demais: não é mania exclusivamente dos chinezes. Como ficou acima dicto, sustenta Mussolini que só detestam a guerra os covardes. Mas, desde já devo adeantar que a guerra opera uma selecção ás vessas: leva os melhores, como se proclamou tantas vezes durante a última guerra, a chamada grande guerra.

Si é certo que sobre estas causas das guerras é muito difficil actuar a obra de educação para a paz, julgo ser muito mais facil combater os elementos psychologicos determinadores das luctas entre os povos.

Colloca-se, dentre estes, em $10^{\circ}$ logar, o culto aos heroes. Fascina-se o alumno na escola com as narrativas dos individuos que maior damno fizeram á humanidade, e crescem os 
educandos pois nesta atmosphera de enthusiasmo pela destruição de quanto fizeram os homens laboriosos. Não é difficil de prever a consequencia de uma tal educação. Em 2. logar, aponta BARNes o patriotismo mal entendido, que é uma modalidade do anterior motivo para guerras, a falsa crença na superioridade da raça, tão bem pintada na Débâcle de Zola. Enfim indica o estudo da Historia pelo aspecto nacionalista. $E^{\prime}$ o que influe mais sobre o povo, que se mostra sempre inclinado ao nacionalismo: exemplo ha em França com o chauvinismo, nascido sem duvida das lendas sobre a grandeza de Napoleão 1.․

Vou mencionar os coefficientes sociologicos: são o producto de lucta de interesses. São estes comtudo mais internos do que internacionaes. Assim quando os alliados pretenderam privar a Allemanha de sua freguezia, quando se dizia que o imperador Guilherme se transformára em caixeiro viajante, enganavam-se seus inimigos suppondo que a victoria na guerra privaria as nações vencidas dessa vantagem.

Os motivos economicos são os mais dignos de attenção. Em 1. logar, ha a procura de mercados para collocação de productos, caso a que acabo de referir-me tractando dos factores sociologicos, e a busca de materias primas, importação de materias para industria e exportação de productos manufacturados. Em 2. logar, ha o emprestimo de capitaes estrangeiros que gera a intervenção dos grandes Estados, e grandes potencias nos negocios dos paizes mais fracos, cujos subditos ou cidadãos se constituiram devedones de capitalistas estrangeiros. E' o caso da doutrina Drago, formulada para defesa dos povos americanos que deviam aos europeus. Entrelaçadas se acham estas causas, e umas são tambem consequencias das outras. A 3. ${ }^{\mathrm{a}}$ causa economica da guerra sangrenta é a de tarifas, processo summamente irritante, e que accentua o odio dos nacionalistas. Dada essa multiplicidade de causas, é claro quão difficil é luctar pela paz. Como será possivel combater todas essas tendencias instinc- 
tivas do povo rude, geradas do nacionalismo? Como será admissivel appareça o sol que illumine o mundo sem a ambição dos capitalistas? Como esperar que a gloria de mandar não mais actue sobre os actos dos homens? Ha comtudo certas causas que podem ser com relativa facilidade combatidas pelas autoridades. Uma dellas é a dos alarmistas industriados pelos vendedores de armas. A essa causa se re$f \in$ re varias vezes Allen em sua preciosa obra com o titulo "War behind the Smoke Screen" Diz que, em 9 de Fevereiro de 1917, no Congresso dos Estados Unidos, foi denunciado que certos capitalistas norte-americanos influiam na imprensa para o preparo da guerra, explorando paixões $\mathbf{e}$ preconceitos do povo americano! Aqui mesmo no Brasil, difficil será encontrar quem ignore o que têm feito os armamentistas para inimistar-nos com os argentinos. Esta causa classificada por BARNES entre as economicas pode ser combatida por leis bem applicadas.

Expostas as principaes causas de guerra, direi duas palavras sobre a campanha que se tem emprehendido em prol da paz, mas só do ponto de vista da iniciativa particular. A obra de Lobingier "Educating for Peace" é realmente tudo quanto conheço de melhor sobre a materia, sem menosprezar o que acerca do assumpto diz incidentemente BARTHÉLEMy DE Ligt (Contre la Guerre Nouvelle, pags. 109 e s. e passim). Quero porém fazer minhas reservas quanto a alguns remedios nellas indicados por LobINGIER e LigT. Um delles que me parece perigosissimo é o de combater o velho conselho: "Si vis pacem, para bellum". Tem-se dicto que o melhor modo de preparar o espirito pacifico é desarmar-se o povo. (Denwinges, La Farce du Désarmement). Perigosissimo me parece o alvitre, uma vez que em outros povos dominam factores sinistros determinadores das luctas sangrentas. 0 desarmamento do povo pelos governos só se explica pelo medo das revoluções: tudo o mais é pretexto. Não devem os meus patricios ser levados a esta excessiva confiança no espirito de cordura dos outros povos: "Nimia fiducia ca- 
lamitati esse solet" Não são de esquecer aquellas tristes palavras do melancolico autor da Eneida:

"O nimium caelo et pelago confise sereno, Nudus in ignota, Palinure, jacebis arena"

Tambem não creio seja aconselhavel esta constante approximação entre os individuos de origens differentes, forçando a natureza. Em todos os logares onde ha immigração, invasão pacifica, accende-se a xenophobia, de que resultam morticinios, luctas entre indigenas e alienigenas. Nas colonias, vê-se com quanta difficuldade se fundem ou caldeiam os originaes da metropole e os filhos do paiz. Como provar a um branco que elle é homem em condições identicas a um africano? Pode isto entrar na cabeça de um homem superior, mas de individuo do povo. não creio.

Essa fusão só se poderá fazer lentamente. Dos diversos processos que conheço ainda o mais efficaz é o que appella para o sentimento de conservação, de bem estar, que existe em todos os homens. Nada melhor do que a obra "Débâcle" de Zola e a "Nada de Novo na Frente Occidental" de Remarque. No mesmo sentido da obra de Remarque, ha um grande numero de outras na literatura franceza, como sejam "Soirées" de Medan, collectanea de varios literatos, Robert Helmont de Daudet e outras menos celebres, mas não menos efficazes para incutirem horror á guerra. Dos trabalhos scientificos, citarei: Langevin, "Les Methodes Modernes de Guerre", Henri Le Wita, "Guerre Chimique", Sorb, "La Guerre qui vient" Si o interesse leva o homem á lucta, quer para o saque, quer por qualquer motivo economico ou de vangloria, o certo é que o deterá o temor dos horriveis soffrimentos da guerra. Refiro-me á maioria dos homens, porque, como disse acima, sempre haverá alguns que queiram combater pelo prazer da lucta: é a guerra pela guerra.

Mas, voltando ao começo deste artigo, direi que me parece que as mães, irmans e esposas são as que maior impor- 
tancia terão na propaganda contra as guerras: "bella matribus detestata" (Krehbiel, Allen e Barthélemy de Ligt, supra citados). Só a acção particular, só a intervenção suasoria individual poderá conter os que pregam, em bôa fé, pela imprensa, as virtudes da guerra, como, por exemplo, fez Paulo Prado em seu "Retrato do Brasil": impossivel é ao poder publico impedir a manifestação de idéás respeitaveis, ainda quando erroneas, como é esta de que só uma guerra será capaz de elevar o caracter do brasileiro, sob pena de ser violada a respeitabilidade de manifestação do pensamento.

Tornando porém á obra de LoBingier, direi que ella expõe a educação pacifista a ser feita na familia, no lar domestico, assim como a que será aconselhavel na escola, e até na sociedade politica pelo aspecto dramatico, espectaculoso, ferindo a imaginação do povo. Esta ultima fórma liga-se intimamente com a leitura das obras acima citadas, obras que só podem agir sobre as classes elevadas da sociedade, as unicas que lêem Remarque, Zola, Daudet, Langevin, LE Wita, etc.

Mas si aconselho ás senhoras uma lucta indefessa contra a guerra, devo dizer mais uma vez que não creio se possa deixar de acautelar o paiz contra uma aggressão, coisa em que, em geral, como bem diz Ihering, só se crê, quando se ouve o primeiro tiro de canhão (Ludwig Bauer, "La Guerre est pour Demain", trad. de Henry).

Já no meu livrinho "Do Regimen Democratico" occupeime, algum tanto extensamente, com o modo de organizar-se a defesa nacional. Nada tenho a ajuntar sinão que, nestes tempos de pouco respeito a todos, numa sociedade como é a em que hoje vivemos, onde a fermentação das idéas e a lucta de classes têm apagado toda a noção de hierarchia, de superioridade, cumpre-me accrescentar que as leis e os costumes devem augmentar, cada vez mais, as honras militares, e tributar a maior veneração aos que pela patria se sacrificaram. 
Em sua obra "Justiça", observa SPencer que nas sociedades animaes sempre haverá necessidade do sacrificio de alguns de seus membros. Nas sociedades humanas os constantemente sacrificados são os que seguem a carreira das armas, quer por vocação, quer para cumprir um dever civico. Outro argumento muito valioso e convincente na propaganda contra a guerra é o custo della, ser patrimonialmente ruinosa para o povo, o factor economico, em summa (Krehbiel, "Nationalism", pags. 46 e s.). Neste ponto nada superior aos trabalhos de Norman ANGELl, que provou ser a guerra economicamente prejudicial até para o vencedor. Ha quem conteste esta these brilhantissimamente sustentada pelo autor, mas difficil será impugnar com logica o que escreveu o creador do anguellismo (KREHBiel, pags. 36 e s.). A grande illusão, como diz o eminente pacifista, perdura comtudo, como outras tantas erroneas "com que se o povo nescio engana", segundo o immortal epico. Em resumo: educar o povo para evitar, nos limites do possivel, a guerra; mas preparal-o para a possibilidade de uma lucta sangrenta, que me parece ainda de temer em nossos dias. Quero porém que fique bem claro não julgar eu se possa obter segurança de paz, não me suppondo dispensado de, mais uma vez, repetir que espero sómente uma campanha para diminuir a possibilidade de guerra. E' o que, no final de sua valiosissima obra, pede KREHBIEL: "Schemes for diminishing the chance of war" (pags. 232 e s.). Firme estou, além disto, em que a paz armada, por muito onerosa que seja (Krehbiel, pags. 46 e s.), deve conservar-se, constituindo um sacrificio da natureza de tantos outros que faz o povo para manutenção de sua existencia. Guarde-me Deus de aconselhar aos meus compatriotas a imprevidencia que lhes poderá ser de exicio. 